\title{
Learning about concepts through everyday language interactions in preschools
}

\author{
Liv Gjems
}

University College of South-East Norway, Kongsberg, Norway

Corresponding author. E-mail: Liv.Gjems@usn.no

Background. In several Nordic countries, the pedagogy in preschools has a social pedagogical ideal. The focus is on development of social competence, aiming to empower children. There is only minimal focus on teaching and academic learning. The aim of this study is to investigate what kind of support children's concept formation can receive when children are engaged in everyday language interactions with preschool teachers in Norway. Theoretically, the article is based on theories developed from Vygotsky's (1987) perspectives on language as a mediating tool.

Design. Two classrooms with two preschool teachers and 18 children in each class participated in the study. The preschool was chosen because it especially focused on children's language learning.

Method. This study is a qualitative study based on video-taped observations in one preschool, and the data are video-taped observations of language interactions between two preschool teachers and children in two preschool classrooms. Most language interactions in Norway occur in everyday conversations such as play, art activities and meals.

Results. The teachers interacted with the children around topics that engage the children and topics they took initiative to talk about. The teachers invited the children in warm ways to use language to make meaning of the shared topic. However, they seldom presented supplementary concepts or expanded the children's concept understanding with their own knowledge.

Conclusion. The social pedagogical ideal may have made them associate such sharing of knowledge with teaching.

Keywords: everyday language interactions, learning words and concepts, cognition, preschool

\section{Introduction}

The aim of this study is to investigate talk in everyday language interactions and examine what they can represent as arenas for concept formation. Vygotsky (1987) used the term scientific concepts to refer to academic concepts as opposed to intuitive tacit concepts and the names of concrete objects embedded in everyday con- 
texts. He argued that there is a complex relationship between everyday concepts that children hear in everyday language interactions with parents, teachers and peers, and scientific and more abstract concepts.

The Nordic early childhood education is described by Bennett (2010) as a social pedagogical approach in opposition to a pre-primary approach. Such a social pedagogical approach focuses on the development of social competence, aiming to empower children as active participants who can influence their own lives by strengthening their identity and self-esteem. Language interactions occur mainly spontaneously in daily activities, initiated by the children or the teachers, without any planned intentions or aims. Usually, approximately 20-30 minutes a day can be used for teacher-led planned activities. Accordingly, the most frequent situations for language interactions occur in everyday activities, and everyday activities represent important language learning situations in preschools in Norway as well as in the other Nordic countries.

\section{Learning everyday concepts and scientific concepts in daily activities}

From a socio-cultural perspective, learning is regarded as situated, and experiences such as joint activities that promote talk are seen as important means for both conveying meaning and generating new meaning (Nelson, 1995; Rogoff, 1998). Sociocultural theories claim that language represents our most important mental function (Fleer, 2009), and Vygotsky (1981) described human thinking as linguistic thinking, and concepts as the meaning of words. He stressed especially the meaning of words, because in thinking, we use the meaning of words. Vygotsky (1981) suggested that higher mental functioning has its origins in social processes mediated by tools and signs, and particularly by language. Vygotsky had a different perspective on conceptual learning than Piaget who believed that children's learning about concepts and their surroundings were results of inner thought processes through assimilation and accommodation (Rogoff, 1998).

In the early years, language interactions between preschool teachers and children in different everyday activities represent the most meaningful places for hearing and using words and concepts (Rogoff, Paradise, Arauz, Correa-Chávez, \& Angelillo, 2012). Everyday language interactions are frequently occurring situations and can be used as a primary tool for language development and concept formation in Norwegian preschools. According to August, Carlo, Dressler and Snow (2005) and Dickinson, McCabe, Anastasopolulos, Peisner-Feinberg and Poe (2003), opportunities for children to talk with teachers and receive feedback is of great importance for their language learning and concept formation. Siraj-Blatchford (2007) found that qualified staff that did take an active role as language participants supported children's search for understanding coherence and continuity between experiences and language.

This study is built on theories developed from Vygotsky's perspectives (1987) on language as a mediating tool. He asserted that scientific concepts or theoretical concepts are primarily learned through language, while spontaneous concepts are acquired in everyday contexts and systematically built up only to a small degree. His theory suggests that preschool teachers should use language to support the creation and extension of children's word knowledge and that teachers' talk should 
be geared to the needs of the child (Hasan, 2005). Vygotsky (1987) claimed that everyday concepts include knowledge of everyday situations, such as knowing that we call almost all creatures with four legs and fur animals, though children may not know what elements are necessary to draw this conclusion. In this study, abstract concepts are given equal status as scientific concepts as they are both abstract concepts and can be used across contexts, and they do not exist in everyday practice.

\section{Moving from everyday concepts to abstract, scientific concepts}

Vygotsky (1987) claimed that everyday concepts develop from below to above, while scientific concepts develop from above to below, and that they are strongly connected to each other. Everyday concepts are grounded in everyday language and life experiences, while scientific concepts constitute the structural formation necessary for the strengthening of everyday concepts. Children's language learning constitutes an important part of cognitive development and concept formation (Borovsky \& Elman, 2006; Wells, 1994). To include a word into a system of a concept, children have to understand that for an object to be categorized as a member, they have to have some traits in common with the other members of the system (Fleer, 2009). For instance, animals have mainly four legs, a tail, a snout and some kind of fur. At the same time, they must accept that the members in a category also have some differences, as in size, color, appearance and behavior. To identify an object as a member of a system or concept, a child must master looking away from differences between the members of the system, and instead look for relevant similarities (Wells, 2008).

Nelson (2007) claims that the greatest challenge for children is learning abstract and scientific concepts higher up in the conceptual hierarchy than learning concrete ones, since these concepts do not exist in the physical world. Children must learn abstract concepts through definitions or by getting several experiences with hearing a concrete concept named together with the corresponding abstract concept (Kontos, 1999). Understanding that a word, representing a concept, symbolizes a trait that is shared by all objects in a category, transferable from context to context, will support a child in understanding some aspect of new situations. Vygotsky (1987) claimed that such generalization of word meaning is related to thinking, and he noted that the meaning of a word is connected to the domain of thought as well as the domain of speech. A word without meaning is not a word, but an empty sound. A word's meaning is both speech and thoughts, and Vygotsky used the expression verbal thinking for such cognitive processes. Vygotsky (1987) meant that it is fruitless to directly teach or instruct preschool children about scientific concepts: "under these conditions children learn not the concept, but the word, and this word is taken over by the child through memory rather than thought" (Vygotsky, 1987; p. 170). When children learn scientific concepts away from the context in which they are used, scientific ideas and thinking becomes separated from everyday practice. Preschool teachers can support children's learning about abstract concepts when they grasp an opportunity to prolong a language interaction in situations when the children are engaged in activities (Wilcox-Herzog \& Kontos, 1998), when they participate in play and reading aloud settings, and when the children invite the teacher to talk about something (Dickinson, 2011). 


\section{Research question}

This study aimed to examine how preschool teachers, through everyday talk, can support children's understanding of the connection between everyday concepts and abstract, scientific concepts. In Norwegian preschools, the topics of everyday talk address all types of subject areas in which either the children or teachers are engaged. The research question in this study is: How can preschool teachers support children's early experiences with abstract and scientific concept formation in everyday activities?

\section{Method}

\section{Background}

This study employs video-taped observations of everyday talks to investigate how two preschool teachers promoted children's language learning and concept formation in two classrooms in a small-town public preschool. All parents and staff signed a written, informed consent accepting the research and use of video filming. Spontaneous and informal everyday language interactions were chosen as situations for observation because they are the most frequent arena for language interactions in Norwegian preschools. Everyday language interactions occur in many activities such as meals, play, in the cloakroom, and in arts and craft activities, and they can be initiated by either the teachers or the children (Weizman \& Snow, 2001). The focus was on the content of the interactions. A previous incident, an association or a prolonging of the previous speakers topic could give grounds for talk initiation (Wasik, Bond, \& Hindman, 2006).

\section{Settings}

The preschool consists of four classes. Two classes with children ranging from three to six years of age who agreed to participate. The classes comprise 18 children, with one preschool teacher and two teacher assistants. The children came from families with parents, mothers and/or fathers working in different areas, and none of the parents was particularly poor or particularly rich according to Norwegian standards.

The observations were conducted one day a week from 8 am to 11 am over a period of four months, for a total of 12 visits. The study was accomplished using video-taped observations over a period of four months, and a handheld video camera was used. I was sitting close to the teachers while they were interacting with small groups of children engaged in some type of everyday activity, and I attempted to interfere as little as possible in classroom activities during my visits.

\section{Analysis}

The talks were transcribed according to the Child Language Data Exchange system (MacWhinney, 1991), and the transcripts were marked for overlapping utterances, pauses, pace, emphatic stress and intonation (falling and rising intonation). Talks and language interactions are defined as a group of semantically contingent utterances between two or more speakers that comprises multiple turns on the same topic (i.e., each speaker talks at least one time) (Ninio \& Snow, 1996). An utterance 
is defined as the smallest unit of speech; it is primarily defined by intonations, and second, by the permanence of pauses. Utterance boundaries were based on intonation contour and pause duration, and the contextual information needed to understand the interaction and inaudible utterances was included in the transcripts. A turn was defined as what one speaker says about a particular topic and may include several consecutive utterances.

The analyses started by focusing on the teachers' engagement when talking with the children. Then, we examined whether and how preschool teachers supported the children's learning about the concepts by introducing a more abstract concept higher in the concept system from the subordinate concept the children used. Their language support, the words they used to support the children's formation of concepts, was examined, and bodily communication was studied to get an impression of the climate of and engagement in the relationship.

\section{Results}

The data comprised 12.5 hours of video-taped observations, and the data material consisted of 26 transcribed language interactions lasting from two to six minutes, for a total of 82 minutes. Fourteen of the talks were filmed in one classroom (Teacher 1) and 12 were filmed in the second classroom (Teacher 2). Only three of the conversations were about the meaning of words. The examples below are the only ones in the material where the two teachers and the children were engaged in spontaneous language interactions talking about the meaning of words.

\section{Connecting experiences and abstract and scientific concepts}

The first excerpt is from a conversation between a teacher (Teacher 1) and two children, Jan 4.2 years and Per 3.7 years, as they sit at a table eating breakfast. It is in the middle of November, and there has been some early snow covering the ground. The teacher and Per talk about a car he has placed on the table, and Jan is looking out of the window. Jan then introduces this topic:

1JAN: you know what I think -? [= engaged, talks load, addressed to the teacher]

2TEA: [ smiles, shakes her head]

3JAN: it is too early for winter $-!$ [ = decisive tone]

4TEA: too early - ? [ = surprised, interested tone]

5TEA: why -? [= inviting, looks at Jan and smiles, waits for five sec]

6JAN: because there are - there are some leaves on a tree- [= talks slowly]

7JAN: and there should not be leaves $-!$ [= indignant tone]

8TEA: no -? [= looks at Jan, waits for six seconds]

9TEA: and there are leaves $-?[=$ confirming tone]

10JAN: yes -. [= smiles, nods, relieved?]

11PER: it doesn't matter $-!=$ [comforting and explaining tone]

12TEA: leaves on the trees are typical autumn yes $-![=$ nods, smiles at Jan]

13TEA: and snow - [= interrupted of Jan]

14JAN: is winter $-!$ [= jumps from his chair, and smiles at Per and the teacher] [= Per and Jan start talking about playing in the snow] 
In line 3, Jan introduces the topic of winter, and shares his thoughts about what the autumn and the winter should be like. He seems to be disappointed about the snow on the ground and relates this snow to the winter coming too early. In line 5 , the teacher challenges him to explain why he thinks winter has come too early. Jan explains his thoughts to her in lines 6 and 7. The teacher communicates in line 8 that his answer surprises her when she asks "no?" She then waits for six seconds for him to think about what to answer. When he does not continue, she repeats his utterance from line 6 and line 9, and Jan confirms her saying that leaves on the trees are wrong in his understanding of winter. The teacher communicates that she accepts his answers. Jan is introducing elements related to how we define winter and claims that the winters should be without leaves on trees. By making this statement, Jan reveals that he has some knowledge about winter as an abstract concept referring to seasons. He underlines that winter is different from autumn, and communicate that he has some understanding of the concept "season", a concept that is even more abstract. In line 12, the teacher communicates that she agrees with Jan, that leaves on trees is typical in autumn, and she starts with confirming what is typical winter, when Jan fulfils her sentence and seems happy, introducing a talk with Per.

This spontaneous talk about what characterizes winter is introduced by Jan while he is looking out of the window. The teacher acknowledges and supports his utterances and communicates that she is engaged in Jan's thoughts about the winter coming too early. She turns her attention towards him, asks him the openended question "why", and she leans towards him and makes eye contact. She also provides him time to find answers to her questions. The teacher communicates that what he says engages and surprises her. Her supportive style may have inspired Jan to think through what winter is about, and his explanation is based on an element, leaves on the trees, we usually think of when we separate autumn from winter. He both introduces a scientific concept, winter, and argues for his points of view. His understanding about winter is probably related to a common, abstract and scientific understanding of winter as white all over, no leaves, no grass and no flowers. Jan categorizes his experiences by defining signs of autumn and winter. Talking about his observations with the teacher, and by getting acceptance for his explanation of an observed phenomena, Jan's understanding of winter as a scientific concept is probably both confirmed and expanded. The teacher supported his thoughts, but she did not expand on his concept by presenting more differences between the two concepts.

The next example is from a conversation between a teacher (Teacher 2), Ari 3.2 years, Ole 5.3 years and Ida 3.5 years. The teacher, Ola and Ida are sitting around a small table and playing with building blocks when Ari arrives. He has with him a book his mother has read to him, and the excerpt is from the conversation following Ari's talk about the book that he calls a naughty book:

1TEA: so is it about naughtiness -? [= engaged, smiles at Ari]

2ARI: yes -! [= aloud, looks proud]

3TEA: okay - but what do you do when you are naughty then -? [= interested tone, leans towards Ari]

4ARI: you hit when you get angry and such -. [= explaining tone] 
5TEA: is that to be naughty -? [= she looks surprised at Ari and Ida]

6ARI: uhum - [= nods]

7TEA: what do you think Ida -? [= smiles at Ida, inviting, both Ida and Ole follow the interaction]

8IDA: being angry -? [= questioning, looks at the teacher, Ole and Ari]

9TEA: being angry -? [= inviting, looks at Ida]

10IDA: yes - [= nods, does not look up from the blocks]

11TEA: what do you do when you are angry then Ole -? [= inviting, smiles at Ole]

12OLE: hit -! [= quick and assertive, proud voice]

13TEA: hit - [= serious, nods, looks out of the window, it is quiet for six seconds]

14IDA: when I am a baby I kick and hit and scream -! [= creeps together and talk with a baby-like tone, Ari and Ola look resigned at the teacher]

15TEA: do you want me to read the book now -? [= the children nod]

16TEA: maybe we can hear what other children do when they are naughty -? [= the children gather around the teacher and look in the book]

The teacher invites Ari to tell her what he thinks we do when we are "naughty". In line 4, Ari answers that it means that you hit "when you get angry and such". Ari shows here that he knows what the abstract concept "naughty", which is related to the even more abstract concept of behavior, may represent. The teacher then invites the two other children into the conversation. In line 7, she asks Ida what she thinks, and Ida answers, or asks, in line 8 , that she think that "to be naughty" means to be angry. The teacher accepts her definition and uses her utterance "being angry" when she turns to Ole. She asks Ole what he is doing when he gets angry. In line 12, Ole answers that he hits when he is angry. Both Ida's and Ole's answers are based upon Ari's saying that naughtiness is about being angry and to hit. Naughtiness is an abstract concept and they all seem to agree that the two suggestions, being angry and to hit, are part of the concept "naughty".

The three children seemed engaged in the topic, and look at each other and the teacher while talking. They related their everyday experiences with doing something probably disobedient and using unacceptable behavior, such as being angry and hitting, with the abstract concept naughty. Both Ole and Ida answered in accordance with Ari's saying in line 4, "you hit when you are angry", and their associations with naughty are probably linked to these words. Their experiences from everyday practice are creating the potential for an abstract and scientific understanding of the word naughty and the environmental views of accepted and non-accepted behavior. This conversation may both have confirmed and expanded their understanding of the word naughty. Ida seemed uncertain when combining naughty with being angry, but the teacher confirmed her saying by sending it further to Ole. Ole connects "to be angry" with "to hit", and seemed quite sure about this answer. The teacher communicates through her body language that she accepts their answers, though they seemed to surprise her. The children have experiences with relating concrete experiences such as being "angry and to hit" with the abstract concept "naughty". The teacher seems to let the reading of the book represent any further expansion of the concept. She could also have expanded the meaning by presenting some of her own viewpoints. However, the teacher did not expand their ideas of being naughty by suggesting ruder behaviors. 
The following excerpt is from a talk, in which the teacher dwells upon a superior and abstract concept used by one of the children. A teacher (Teacher 1) and two children, Eva 4.3 years and Mia, 3.1 years, are sitting together at a table and talking while they are drawing. They are alone in the room, and Eva has just told about a friend of hers who has been ill for two weeks. The teacher then invites the children to talk about the meaning of the word "ill".

1TEA: to be ill -

2TEA: what is it actually, to be ill I mean -? [= no one replies, she waits for seven seconds]

3TEA: what happens when you get ill -? [= exploring tone, inviting]

4EVA: that you can get sick -! [= eager, loud]

5TEA: that you may get sick - uhum -. [= nods, smiles at Eva, it is quiet for six seconds] 6TEA: have you ever been ill Mia -? [= inviting tone, Mia looks down at the table and shakes her head]

7TEA: you haven't -?

8TEA: eeh- have you ever been sick -? [= engaged tone, inviting, waits for 6 seconds]

9MIA: yes - sometimes - [= low voice, look quickly at the teacher, shy?]

10TEA: oh - what happens to you then -? [= engaged, loud, waits for eight seconds]

11MIA: I throw up- [= low voice]

12TEA: you throw up -! [= same low voice as Mia]

13MIA: yes - ! [= louder]

14TEA: how did that feel -? [= smiles at Mia, inviting tone]

15MIA: I don't know -. [= looks at the teacher and Eva, shakes her head]

16TEA: but what is it to throw up then? -? [= exploring tone]

17MIA: I don't know - being ill -? [= looks quickly at the teacher]

18EVA: yes - ! [ = load, proud tone, smiles at Mia]

19TEA: yes -! [= confirming, smiles and nods to Eva. After four seconds, Eva introduces another topic]

In this excerpt, after Eva has spoken about her friend being ill, the teacher attempts to make the children formulate what it means to be ill. In lines 1 and 2, she asks what the word actually means, and she gives the children enough time, seven seconds, to think about the answer. When they do not answer, she concretizes the concept some more in line 3 by asking, "What happens" when we get ill. Eva demonstrates in line 4 that she has acquired an understanding of some of the core elements that characterize the knowledge related to the concept of "ill". Eva shows that she understands that the abstract concept of being ill is related to the concept of physical health and has to do with bodily conditions. In this way, she displays an understanding of classification and that she is able to categorize sick as one way of being ill. In line 4, Eva suggests that what happens is that you can get sick when you are ill.

The teacher accepts Eva's utterance, and turns the topic to the children's experiences. In line 6, she asks Mia if she ever has been ill. When Mia claims that she has never been ill, the teacher takes up the word sick that Eva introduced in line 4, and ask in line 8 if she ever has been sick. In line 9, Mia confirms that she has been sick. Mia does not seem to have made the connection between being ill and being sick. 
The teacher's question about what happens when you are sick in line 10 makes Mia talk about her experience with throwing up in line 11. The teacher's question about how it feels to throw up and what it is seems too difficult, may be too abstract, for Mia to answer. When the teacher asks what it is to throw up in line 16, Mia asks back if to throw up is to be ill in line 17. Mia relates her concrete experience with throwing up to the abstract and scientific concept "being ill", and ends up relating throwing up with being ill. She also seems to have some problem with understanding the phrase "what it is". Both Eva and the teacher confirm her conclusion in lines 18 and 19. Mia may perhaps only have got a limited understanding of the concept "ill". However, this experience will probably support her when she hears this concept in another context.

The preschool teacher elaborates on this topic, which was introduced by Eva, and through sharing experiences and giving each child time to think about what the concept "ill" can represent, the topic was explored. What the concept denotes was elaborated on through the children's talk about their experiences. The preschool teacher uses a warm tone and acknowledges the children by helping them to sort out what "ill" may mean in the light of their experiences. The children got an important experience through this conversation. This talk about "being ill" is about an abstract experience, a phenomenon, absent in the actual context, and both the children seemed interested and engaged in this conversation. They got an experience with talking about an abstract, non-present concept, as well as classifying being sick and throwing up as elements in the concept of "being ill". However, without disturbing the children's engagement, the teacher could have introduced some more well-known sub-ordinate concepts, such as sore throat and fever.

\section{Discussion}

According to Bronfenbrenner and Morris (2007), children's language learning in the early years is dependent upon a close and positive relation to responsive adults. Such a relation is expressed through warm and caring communication, with feedback given with both physical and emotional warmth. Everyday talks that children engage in represent important situations for them to learn about both abstract and scientific concepts (Hasan, 2002). The children in the three excerpts took spontaneous initiative to talk about a subject that engaged them, and the teachers supported them in warm and responsive ways. Dickinson (2011) underlined that engaging language experiences represent rich language learning situations for children. In all three excerpts, the two teachers communicated that they were listening and were interested in what the children uttered, and they prolonged the topics in which the children were engaged. They acknowledged what they said, and the children were invited to prolong their talk about the actual topic. To be attentive represents more than to smile and to nod (Neuman \& Marulis, 2010). According to Dickinson (2011), preschool teachers must have knowledge about in what ways they can invite children to express an idea, prolong their engagement to talk about experiences, and support their talking as well as their thinking about experiences and concepts.

The two teachers asked questions that engaged the children to talk about their thoughts and experiences with abstract, scientific concepts such as the concept winter, as it related to the even more abstract concept season; naughty, as it related 
to the more abstract concept of behavior; and being ill, as it related to the abstract concept of physical health. The teachers did not teach or talk with the children about the many elements that could have been added to the abstract and scientific concepts in focus here. Rather, they based their sayings on the children's own utterances and questions and their naming of elements. They prolonged their topics and invited them to express their experiences and thoughts about them. Through the language interactions, the children received some experience with classification, because the teachers helped them to link an abstract concept to a more concrete concept, or asked the child what he/ she was thinking of when using the concepts. The eldest children, Jan, Eva and Ari, presented examples of how one could classify winter by expecting no leaves on trees, being ill with being sick and classifying naughty with "being angry" and "to hit". The social pedagogical tradition may have hindered the teachers from presenting more examples and taking initiative to extend and prolong the talks about concepts.

According to Vygotsky (1987), classification is an important part of moving from everyday concepts to scientific concepts. When children have experiences with linking concrete subordinate concepts and abstract concepts higher in the system of the concept, this process will represent important experiences for their cognitive development. Acquiring scientific concepts presupposes that children acquire an understanding of the core or central elements that characterize the particular forms of knowledge the concept represents (Nelson, 2009). When a child understands classification, they have gained an understanding of comparison and categorization. The examples show how young children can engage in talk about abstract phenomena and connect their own everyday experiences to words not being physically present in the context. In the talk about winter for instance, Jan talks about winter as a season he has related some abstract and theoretical understanding about, and something is not right when there is snow on the ground at the same time as there are leaves on the trees. Ari associated naughty with doing bad things, and Eva related being ill with an unpleasant experience such as throwing up. All the experiences can be related to core elements in the system of abstract concepts.

Hasan (2002) underlined that most everyday talks occur with little reflection. How teachers talk, and what they talk about in everyday language interactions, represent frequent and accordingly important arenas for children's learning, and challenge preschool teachers to be attentive to that which different children are engaged. The teachers in this study talked with the children about the topics they introduced themselves and in which they were engaged. How teachers talk, and what they talk about in everyday language interactions, represent frequent and accordingly important arenas for children's language learning (Adger, Snow, \& Christian, 2003; Dickinson, 2011). Through the language interactions, the children probably received some experience with classifying single incidences with abstract concepts, such as "throwing up" with "illness". To be attentive to what different children are engaged in represents challenges to preschool teachers. A question to ask is how attentive a preschool teacher can be to 18 different children's efforts to categorize experiences and thoughts and relate their experiences to language in informal, spontaneous language interactions. To manage this process, the teachers in most of their language interactions must direct their attention towards each child's language learning and concept formation. 


\section{Conclusion}

The social pedagogical tradition seemed to dominate the pedagogy in this preschool. There were also relatively few talks where the teachers supported the children's concept formation and use of language. They did not introduce any new concrete or abstract concepts related to the concept system they used in these language interactions. In the social pedagogical tradition, cognition and concept formation received less focus and were of less importance than social competence, and this focus may have reduced the teachers' attention towards their language interactions with the children. Accordingly, there is a possibility that the ideal of not teaching in preschool may have prevented the teachers from sharing, informing and supporting the children learning, even though the children were engaged.

\section{Acknowledgements}

This study is financed by the Norwegian Research Council.

\section{References}

Adger, C., Snow, C., \& Christian, D. (2003). What teachers need to know about language. Center for Applied Linguistics (CAL).

August, D., Carlo, M., Dressler, C., \& Snow, C. (2005). The critical role of vocabulary development for English language learners. Learning Disabilities Research and Practice, 20(1), 50-57. doi: 10.1111/j.1540-5826.2005.00120.x

Bennet, J. (2010). Pedagogy in early childhood services with special reference to Nordic approaches. Psychological Science and Education, 3, 15-21.

Borovsky, A., \& Elman, J. (2006). Language input and semantic categories: A relation between cognition and early word learning. Journal of Child Language, 33(759-790). doi: 10.1017/ S0305000906007574

Bronfenbrenner, U., \& Morris, P. (2007). The bioecological model of human development. Theoretical models of human development. In R. Lerner (Ed.), Handbook of child psychology (Vol. 1, pp. 793-829). John Wiley \& Sons.

Dickinson, D. (2011). Teachers' language practices and academic outcomes of preschool children. Science, 333, 964-967. doi: 10.1126/science.1204526

Dickinson, D., McCabe, A., Anastasopolulos, L., Peisner-Feinberg, E., \& Poe, M. (2003). The comprehensive language approach to early Literacy: The interrelationships among vocabulary, phonological sensitivity, and print knowledge among preschool-aged children. Journal of Educational Psychology, 95(3), 465-481. doi: 10.1037/0022-0663.95.3.465

Fleer, M. (2009). Understanding the dialectical relations between everyday concepts and scientific concepts within play-based programs. Research in Science Education, 39(2), 281-306. doi: $10.1007 / \mathrm{s} 11165-008-9085-\mathrm{x}$

Hasan, R. (2002). Ways of meaning, ways of learning: Code as an explanatory concept. British Journal of Sociology of Education, 23(4), 537-548. doi: 10.1080/0142569022000038396

Hasan, R. (2005). Language, society and consciousness. London: Equinow Publications.

Kontos, S. (1999). Preschool teachers' talk, roles and activities settings during free play. . Early Childhood Research Quarterly, 14(3), 362-382. doi: 10.1016/S0885-2006(99)00016-2

MacWhinney, B. (1991). The CHILDES Project: Tools for analyzing talk. Hillsdale, NJ: Lawrence Erlbaum. 
Nelson, K. (1995). From spontaneous to scientific concepts: Continuities and discontinuities from childhood to adulthood. In L. Martin, K. Nelson, \& E. Tobach (Eds.), Sociocultural psychology: Theory and practice of doing and knowing. (pp. 229-249). Cambridge: Cambridge University Press.

Nelson, K. (2009). External representations critical to human intelligence. In C. Andersen, M. Echeverria, \& N. Scheuer (Eds.), Representational systems and practices as learning tools (pp. 297-313). Rotterdam: Sense Publishers.

Neuman, S., \& Marulis, L. (2010). The effects of vocabulary intervention on young children's word learning: A meta-analysis. Review of Educational Research, 80(3), 300-335. $10.3102 / 0034654310377087$

Ninio, A., \& Snow, C. (1996). Pragmatic development. Oxford: Westview Press Inc.

Rogoff, B. (1998). Cognition as a collaborative process. In W. Damon, D. Kuhn, \& R. Siegler (Eds.), Handbook of child psychology. Volume 2: Cognition, perception and language. (pp. 679-744). New York: Wiley.

Rogoff, B., Paradise, R., Arauz, R., Correa-Chávez, M., \& Angelillo, C. (2012). Firsthand learning through intent participation. Análise Psicológica, 22(1), 11-31. doi: 10.14417/ap.126

Siraj-Blatchford, I. (2007). Creativity, communication and collaboration: The identification of pedagogic progression in sustained shared thinking. Asia-Pacific Journal of Research in Early Childhood Education, 2, 3-23.

Vygotsky, L. (1987). Thinking and Speech. In T. R.W. Rieber, A.S. Carton, \& N. Minick (Eds.), The collected work of L.S. Vygotsky (Vol. 1, Problems of general psychology, pp. 39-285). New York: Plenum Press.

Vygotsky, L. (1981). The genesis of higher mental functions. In J. Wertsch (Ed.), The concept of activity in Soviet Psychology. (pp. 144-188). New York: Sharpe.

Wasik, B., Bond, M. A., \& Hindman, A. (2006). The effects of a language and literacy intervention on Head Start children and teachers. Journal of Educational Psychology, 98(1), 63-74. doi: 10.1037/0022-0663.98.1.63

Weizman, Z., \& Snow, C. (2001). Lexical output as related to children's vocabulary acquisition: Effects of sophisticated exposure and support for meaning. Devlopmental Psychology, 37, 265-279. doi: 10.1037/0012-1649.37.2.265

Wells, G. (1994). The complementary contributions of Halliday and Vygotskij to a languagebased theory of learning. Linguistics and Education, 6(1), 41-90. doi: 10.1016/08985898(94)90021-3

Wells, G. (2008). Learning to use scientific concepts. Cultural Studies of Scientific Education, 3, 329-350. doi: 10.1007/s11422-008-9100-6

Wilcox-Herzog, A., \& Kontos, S. (1998). The nature of teacher talk in early childhood classrooms and its relationship to children's play with objects and peers. Journal of Genetic Psychology, 159 (1), 30-44. doi: 10.1080/00221329809596132

Original manuscript received August 11, 2017 